\title{
EXPERIMENTAL STUDY ON THE CREEP BEHAVIOR OF HYBRID NANOCOMPOSITES
}

\author{
${ }^{*}$ Raad Abd AL-Hassan ${ }^{1}$ \\ Ehsan Sabah Al-Ameen² \\ Dr. Laila Matar Nasser ${ }^{3}$ \\ 1) M.Sc. student, Mechanical Engineering Department, College of Engineering, Mustansiriyah University, Baghdad, Iraq \\ 2) Assist. Prof, Mechanical Engineering Department, College of Engineering, Mustansiriyah University, Baghdad, Iraq \\ 3) Assist. Prof. Dr., Mechanical Engineering Department, College of Engineering, Mustansiriyah University, Baghdad, Iraq
}

\begin{abstract}
In this paper, the influence of adding hybrid nanomaterials (multi-walled carbon tubes with silicon carbide) to composite materials was studied on creep behavior at room temperature and constant load of (147.15) MPa. Hybrid nanocomposites (multi-walled carbon tubes with silicon carbide) were prepared by dispersing (MWCNTs-Sic) in epoxy with different weight fractions (1and $2 \% w t$.) using (sonication device). The composite materials under study were prepared by reinforcing the resulting composite material by three layers of two-way (0-90) fibers glass using the vacuum bag technique. The test specimens were prepared according to standards (ASTM). The samples were tested by a creep test device that was designed and built (according to laboratory specifications and standards). The results showed an improvement in creep behavior by about $8 \%$ and $13 \%$ for the specimen with hybrid nanocomposites (MWCNTs-Sic) (1\%wt.) and (2 \%wt.) respectively.
\end{abstract}

Keywords: Creep Behavior; Hybrid Nano materials; multi-walled carbon tubes; silicon carbide; Fiberglass; Epoxy.

\section{Introduction}

There are many materials that have rare combinations with their properties that are needed by many modern technologies that cannot be found with common minerals, alloys, ceramics, and polymeric materials. The foregoing can be applied to the materials required for transportation, space, and underwater applications [1]. Composite materials are produced by mixing two or more materials to create a mixture that gives more properties [2]. Hybrid compounds can be defined as comprising more than one type of reinforcing material within a single matrix [3]. In recent years, an effort has been made to enrich knowledge of material properties and that information related to creep behavior is limited to structural composites. Many studies and researches focus in particular on analyzing creep behavior in relation to the composite materials and the possibility of enhancing them with fibers, filling and particles [4]. Creep is a deformation inelastic, timedependent, and temperature that occurs when the material is subjected to a constant load (constant stress) [5]. Polymeric nanocomposite are structural materials of the highest importance, in terms of their competitiveness with neat polymers and known compounds. There are many standard compounds that cannot achieve the exceptional properties that nanocomposites 
give. Thermosets nanocomposites are one of the most studied systems, and they have many forms of Nano carbons (carbon nanotubes, graphene, graphene platelets, etc.), which are polymers that contain many nanoparticles [6]. A study was conducted by T. Glaskova, et al. (2009) [7], studied the properties of the creep behavior of epoxy/clay nanocomposite $[\mathrm{NC}]$ beneath the influence of moisture is assessment. The viscoelastic features of $[\mathrm{NC}]$ were examined empirically and their reliance on fillings and moisture influence was determined. The results explained that the value of polymers filled with nanocomposites gives a notable enhancement in creep resistance. The influence of moisture on the performance of creeping polymers that include nanoparticles is yet not obvious and cannot be circulated. Mgbemena C. O., et al (2010) [8], studied of creep behavior of polypropylene / calcium carbonate nanocomposite where a creep test was performed on samples of polypropylene / calcium carbonate nanocomposite in different loads of calcium carbonate $(0 \%, 5 \%, 10 \%$, and $15 \%$ ) by Different stress (13.08Mpa,19.60Mpa and $22.87 \mathrm{Mpa}$ ) and different temperatures (25C,50Cand 70C). creep resistance is very high for polypropylene/CaCo3 compared to the neat polypropylene matrix. The creep Modulus decreases with increasing temperature and time. it is more severe at low-stress levels. M. Tehrani, et al (2010) [9], studied of creep behavior by using (MWCNTs) \epoxy at temperatures (25, 40, 55) $\mathrm{C}$ and three loads (1,2,3) MN. It was noticed that adding $(3 \% \mathrm{wt})$ of MWCNTs enhanced the strength and hardness of the neat epoxy and notable reduction in the creep rate, particularly in high temperatures. The analysis of the creep strain rate sensitivity shows that the addition of MWCNTs to an industrial epoxy decreased the creep rate sensitivity parameter. Yi-Luen Li, et al.(2011) [10], The observed improvement in mechanical properties and creep behaviors by adding CNTs to epoxy/carbon
fiber(CF) under various states of loading, temperature, fiber orientation, contents (CNT), and humidity, explain that these are all factors that critically effect on the creep behavior because creep strain and creep strain rate of CF/epoxy resin laminates increase with the increase of loading, degree of the angle $\theta$ between the orientation of fiber and the direction of the applied stress, temperature and humidity, and the creep strain rate of CNT-added composites reduce with the increase of the amounts of CNTs. CNTs can supply high mechanical reinforcement, and adding a suitable amount of CNTs also can decrease the creep strain rate. Ardavan Z., et al (2012) [11], Investigated of epoxy-based nanocomposites with $0.1,0.3$, and $0.5 \%$ wt. graphene platelet (GPL) nanocomposites. When tested for creep, the nanocomposite with $0.1 \%$ wt GPLs creeps fewer than all other materials, including the neat epoxy at $55^{\circ} \mathrm{C}$ and $20 \mathrm{MPa}$. The creep of the epoxy-GPL system was a distinction with that of epoxy-SWNT and epoxy-MWNT and it was concluded that epoxy-CNT systems creep at the same rate as neat epoxy at high temperatures. The epoxy-GPL creeps significantly less. humidity, and the creep strain rate of CNT-added composites reduce with the increase of the amounts of CNTs. CNTs can supply high mechanical reinforcement, and adding a suitable amount of CNTs also can decrease the creep strain rate. Sohan Kumar Ghosh, et al (2017) [12], studied the performance of creep behavior of fiber glass/epoxy(GF) and thermal flexural and their effect when adding Nano-graphite plates GONP. The creep was tested at different loads $(10,20$ and $40 \mathrm{MPa})$ and different temperatures $\left(50,80\right.$ and $\left.110^{\circ} \mathrm{C}\right)$ to recognize the effect of temperature and stress. Creep resistance improved after the addition of GONP to GE composites, which reduced effect of the temperatures and stress relatively. GONP-GF composites at high temperatures applied stress is 
a crucial role in the creep behavior of these composites. Constantinescu Dan Mihai, et al (2017) [13], Studied the influence of adding silica nanoparticles to three epoxy resins. The weight fraction was $(0.1,0.2$ and 0.3$)$ wt. at constant load, and crawled at room temperature. When increasing the stress level, under load creeping, the static mechanical properties did not improve despite adding different weight ratios from the nanoparticles and the type of epoxy resins. $0.1 \%$ of silica nanoparticles creep less than all materials. the creep rate is decreased by adding silica Nano fillers. In this work the effect of adding hybrid nanomaterials (MWCNT and Sic) to fiberglass/Epoxy composite is studied on creep behavior with variable mixing weights at room temperature.

\section{Experimental Work}

\subsection{Materials and Preparation of Samples}

In this study, the epoxy resin of a trademark (SWISS CHEM) with a density of $1.05 \mathrm{~g} /$ $\mathrm{cm}^{3}$ was used, which is a low viscosity liquid in comparison with other thermoset materials and it is characterized as a free and unpainted solvent, consisting of the base of the liquid epoxy resin (Euxit 50KI) with the hardener (Euxit 50KII) and the mixing ratio (3: 1) by weight fraction as shown in Figure (1). The fiberglass(GF) used is of E-glass type, a two-way simulated fiber mat (0-90) [Woven Roving GF]. It is the most used and more common type because of its ease of production and cheapness, as well as its resistance, high durability, with density of $2.45 \mathrm{~g} / \mathrm{cm}^{3}$, and elongation $4.88 \%$ [14] as shown in Figure 2. The nanomaterials used as hybrid nanocomposite [Multi-Walled Carbon Nano Tubes(MWCNTS) with Silicon Carbide(SIC)]. The multi-walled carbon nanotubes(MWCNTs) were supplied from USA Cheap tubs company. Figure 3. illustrates (MWCNTs). The Silicon carbide was supplied from (HONGU NEW
MATERIAL) company. Figure 4 illustrates Silicon carbide (Sic). The sample manufacturing process goes through the following steps. First, the calculation of the weight of hybrid nanocomposites is according to the weight fraction (1 and $2 \%$ wt.) of the epoxy resin. Second, Nanomaterials were produced by adding (MWCNTs + Sic) to the epoxy. Hybrid nanoparticles are mixed with the epoxy within a magnetic hotplate stirrer for 10 minutes at a speed of 800 r.p.m until the mixture is homogeneous and without bubbles. Third, the mixture is mixed by ultrasonic vibrator (Ultrasonic Cell Crusher Sjia-1200W MTI Corporation) for 25 minutes to disperse nanoparticles uniformly as shown in Figure 5. Then the hardener was added to the mixture with gentle mixing. All samples were manufactured by vacuum bagging techniques with a $35 \%$ volume fraction [volume of fiber glass to composites volume]. Figure 6. illustrates vacuum bagging. Then the specimens have been cutting according to standard dimensions in the ASTMD2990[15], The geometry, dimensions and final shape of the creep specimen used in the study are shown in figure $7(a, b)$.

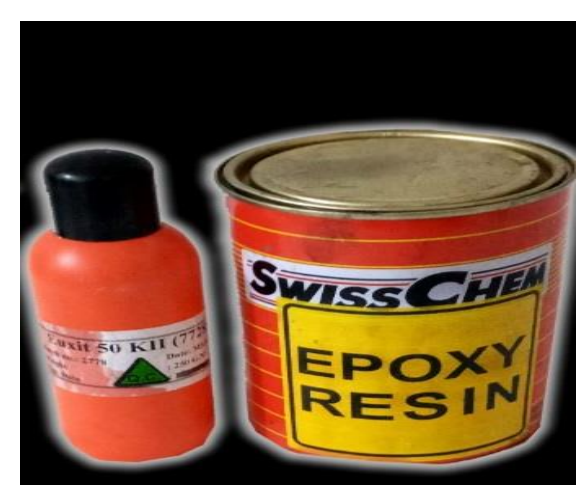

Figure1. SWISS CHEM RESIN. 


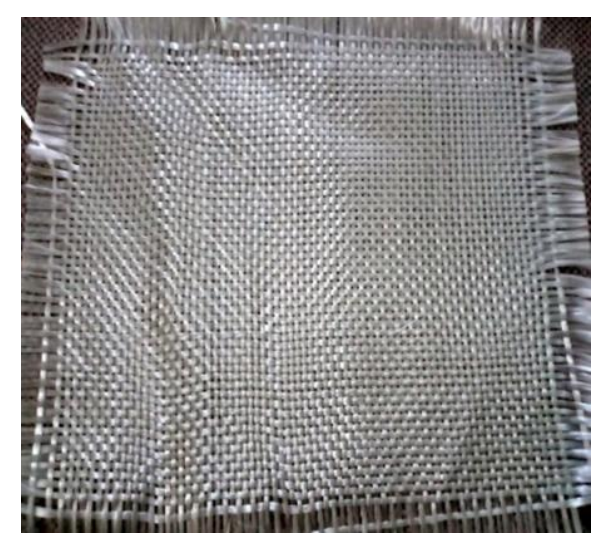

Figure 2. Woven Roving

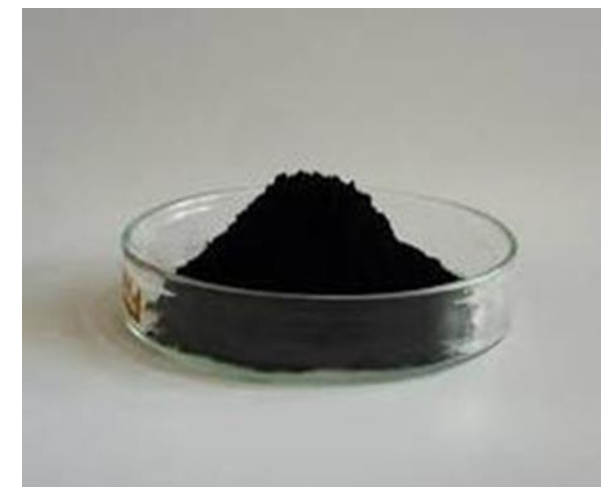

Figure3. MWCNTs.

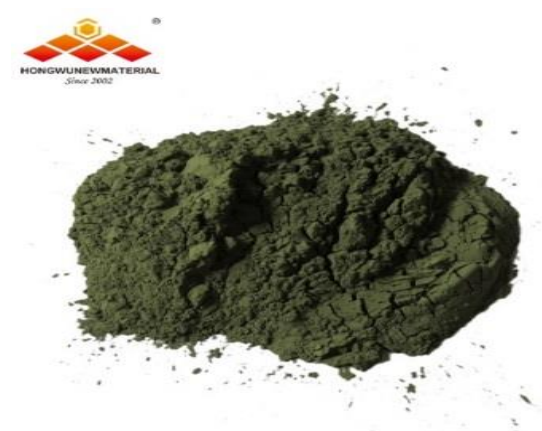

Figure4. SIC Nano powder

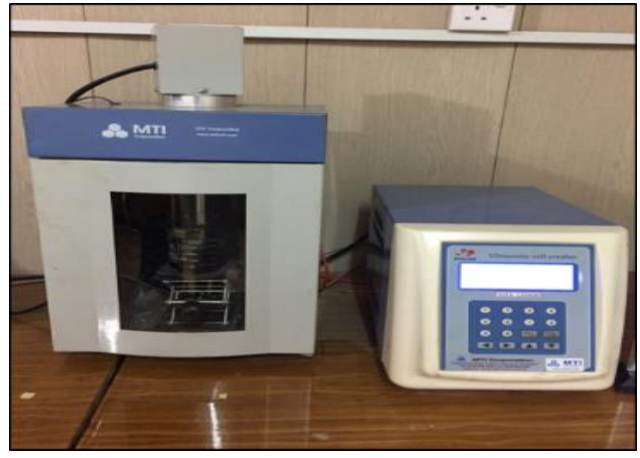

Figure5. Sonication equipment

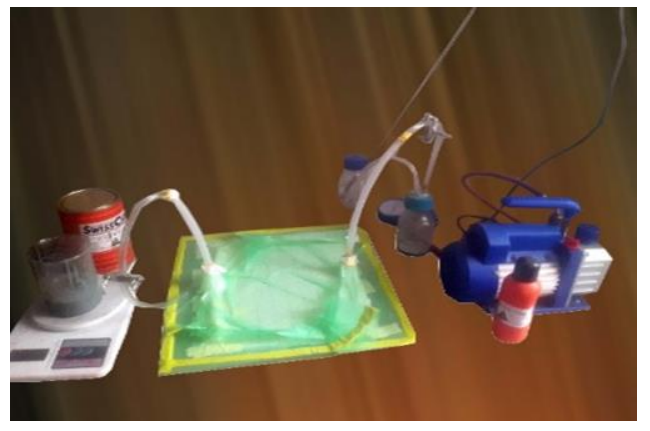

Figure 6. Vacuum bag.

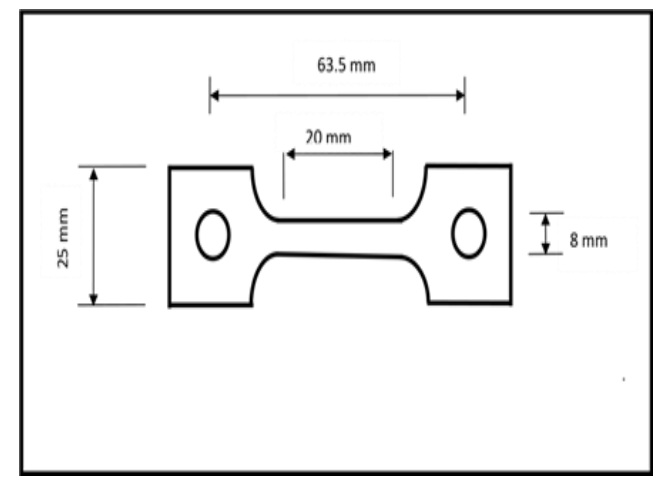

Figure7(a)The geometry and dimensions of the creep 


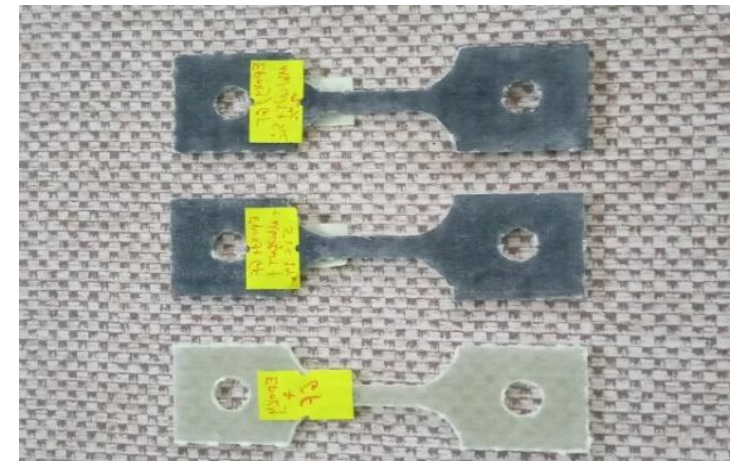

Figure7 (b). Final shape of creep specimen

\subsection{Creep test}

The creep test consists of measuring the strain that depends on time and temperature. The creep test device required for experimental work is designed and manufactured according to laboratory specifications and standards as shown Figure $8(\mathrm{a}, \mathrm{b})$.
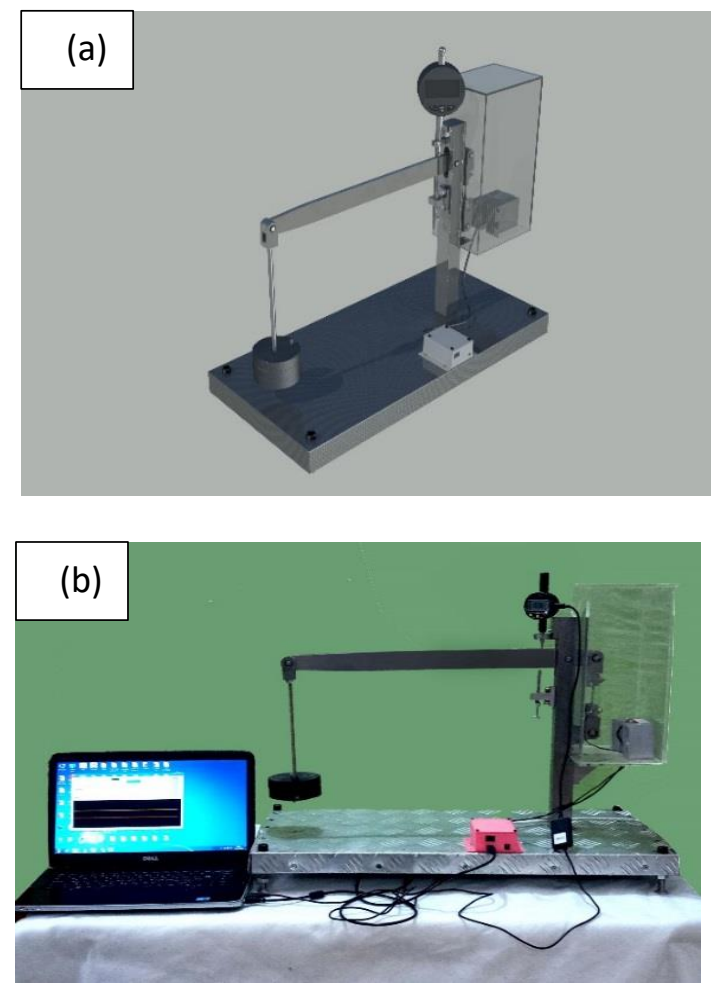

Figure8

(a) an AutoCAD Sketch Drawing for the

Creep Test Device.

(b) The creep test rig.
Then two combinations of material were tested (Epoxy/ three layers' fiber glass) and (Epoxy/ three layers' fiber glass with MWCNT-Sic additives) and the procedure was as follows:

- First, the samples of neat fiberglass/Epoxy were fixed in the creep testing device followed by the hybrid samples. Figure 9 shows the sample fixed in the test apparatus.

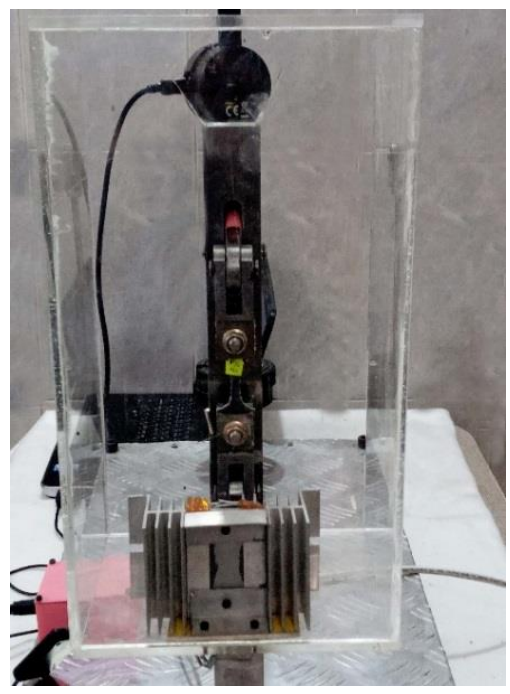

Figure9. Sample in the test apparatus

- A constant load is applied causing a stress of 147.15 MPa at room temperature.

- The sample's elongation is measured by the strain digital system (dial gauge) as illustrated in figure 10 .

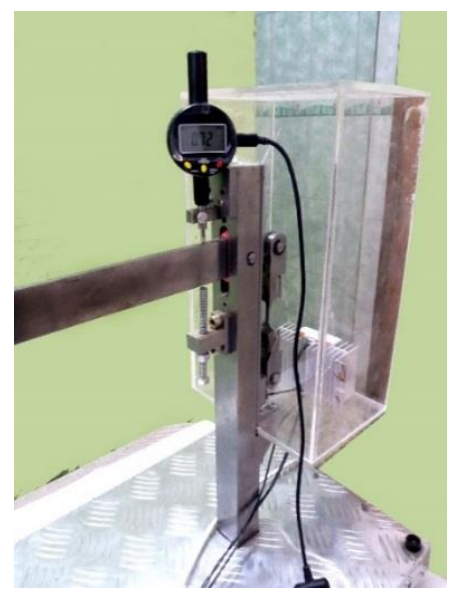

Figure10. Dial gauge. 
The results of the samples deformation due to creep test was used to calculate the strain by the formula

$\varepsilon(\mathrm{t})=\Delta \mathrm{L}(\mathrm{t}) / \mathrm{L}$

$\Delta \mathrm{L}$ is the increasing in the sample's length after applying the load during the time.

$\mathrm{L}$ is the real length of the sample.

Table 1, shows the maximum values from the creep test for 24 hours-As it is shown, when adding (MWCNTs + Sic) to the epoxy matrix, the values of the creep strain were decreased.

Table 1. Maximum creep strain value

\begin{tabular}{ccc}
\hline Wt. of & $\begin{array}{c}\text { Max. creep } \\
\text { Strain }\end{array}$ & $\begin{array}{c}\text { Time } \\
\text { (hr.) }\end{array}$ \\
$0 \% \mathrm{t}$ & 0.119 & 24 \\
$1 \%$ & .11 & 24 \\
$2 \%$ & .1035 & 24 \\
\hline
\end{tabular}

According to this data, it is clear that the addition of nanoparticles (MWCNT + Sic) maintains the structural bonding of epoxy resins as it gives them hardness and sufficient strength for the fiber glass used in the composite materials.

\section{Results \& Discussion}

The strain vs. time behavior was measured for two groups of materials, firstly, woven fiberglass/ epoxy resin (GF). Secondly, woven fiberglass/ epoxy resin (GF) with hybrid nanocomposite ( 1 and $2 \%$ wt.) of epoxy resin, to know the stages of deformation in which it occurs, where a decrease in the area of the crosssection and a continuous increase in the length of the sample due to the increase in stress until the failure occurs, creep depends not only on the value of the applied stress but dependent on the time that is stress applied. Figures 11 and 12 explain the influence of adding the hybrid nanocomposite (MWCNTs, Sic) on the creep behavior(strain-time) relation, based on the experimental results it is noticed that the addition of nanomaterials enhanced the creep behavior of composite material (GF/MWCNT + Sic composite) this is apparent by the low values of strain for the woven fiberglass -epoxy resin with hybrid nanocomposite contrasting with woven fiber glass-epoxy resin without hybrid nanocomposites. because hybrid nanocomposites (MWCNT+ Sic) resist slipping, re-orientation, and polymer chain motion in nanocomposites. That is, it restricts creep deformation because the strength of the Nano fillings composites is highly dependent on the interfacial adhesion between the polymer matrix and the Nano filler that helps transfer a small portion of the stress to the filling particles through deformation [16]. The results of researchers, A. Plaseted, et al (2009) [17], found that the addition $.5 \%$ wt of carbon nanofiber । vinyl ester enhanced creep resistance at constant temperature. Fadhel A., et al (2018) [18], They found that the addition (2,3 and $4 \%$ wt.) of Nano carbon black particles (N220) to the epoxy / carbon fiber improved the creep strain behavior $(10 \%, 12.5 \%$ and $19 \%)$.

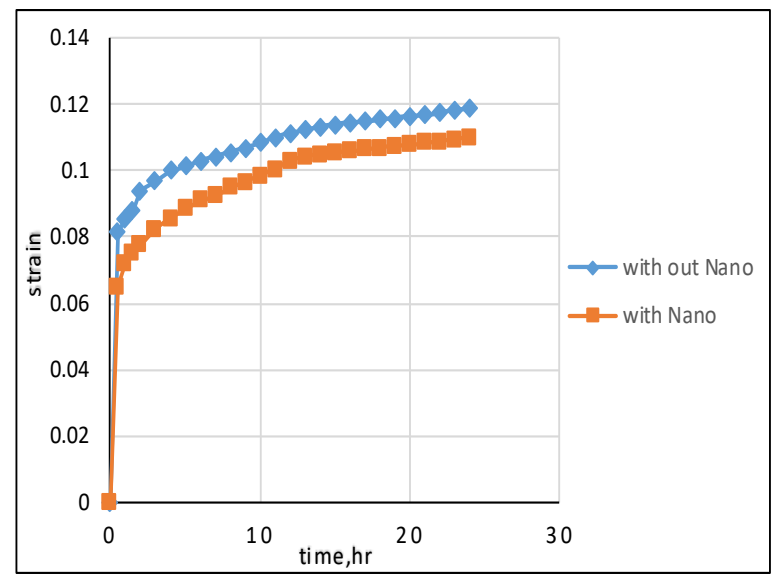

Figure11. Comparative Creep strain (1\%wt.) hybrid nanocomposite $(0.5 \% \mathrm{MWCNTs}+0.5 \% \mathrm{Sic}) \mathrm{wt}$ at 147.15Mpa (ambient temperature of $25^{\circ} \mathrm{C}$ ) 


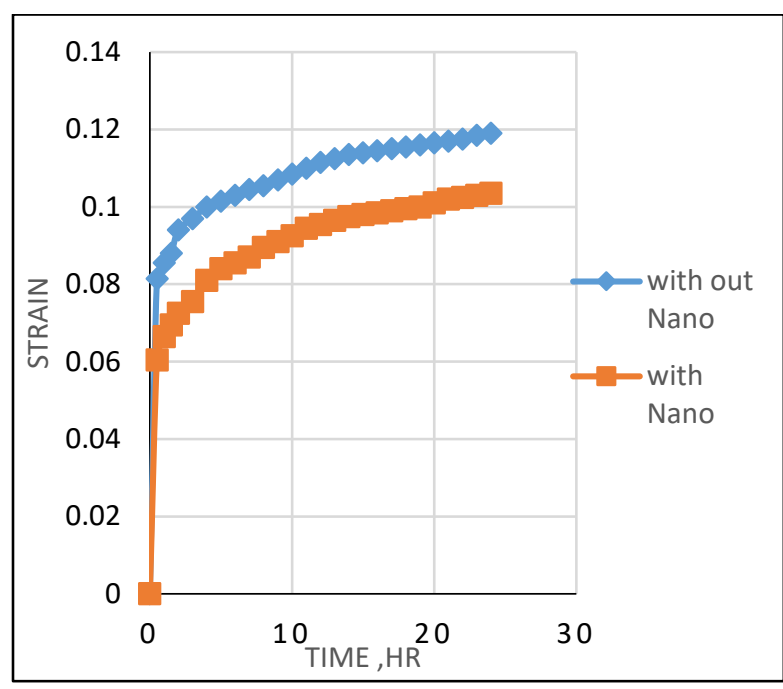

Figure12. Comparative Creep strain (2\%wt.) hybrid nanocomposite (1\%MWCNTs+ $1 \%$ Sic) wt at $147.15 \mathrm{Mpa}$ (ambient temperature of $25^{\circ} \mathrm{C}$ )

\section{Conclusions}

As shown in the figures above, the creep strain behavior experienced an enhancement of about $(8 \%) \&(13 \%)$ for the samples with (MWCNTs + Sic) wt respectively. conclude from this that the nanomaterial additives have a clear effect in improving the creep resistance of the epoxy / fiber class, especially, in used in low weight ratios (1 and $2 \%$ wt.) and that additives are available materials.

\section{Conflict of interest}

The authors declare that they have no known competing financial interests or personal relationships that could have appeared to influence the work reported in this paper.

\section{References}

1. Grujić, A., Talijan, N. M., Stojanović, D., Stajić-Trošić, J., Burzić, Z., Balanović, L., \& Aleksić, R. R. (2010). Mechanical and magnetic properties of composite materials with polymer matrix. Journal of Mining and Metallurgy B: Metallurgy, 46(1), 25-32 Jornal of mining and metallurgy 46 (1) B, pp.25-32, 2010.

2. Mazumdar, S. (2001). Composites manufacturing: materials, product, and process engineering. $\mathrm{CrC}$ press.

3. Totiger, P., Gothe, M., Nagavi, S., \& Mulimani, R. (2015). Comparative study of mechanical and thermal characterization of glass/carbon hybrid composite. Int. J. Res. Eng. Technol, 4(07), 300-307.

4. Hussain, R. K. (2016). Creep Properties of Particles Materials Reinforced Epoxy Composites. Al-Mustansiriyah Journal of Science, 27(2), 56-59.

5. D. j. Davis,L.A Emilian, translated by Dr. Jaafar Taher Al-Haidari and Mr. Adnan Nehmeh, "Metals Structure, properties and thermal coefficients, ". University of Technology, 1989.

6. Constantinescu, D. M., Picu, R. C., Sandu, M., Apostol, D. A., Sandu, A., \& Baciu, F. (2017). Behaviour of Epoxy Silica Nanocomposites Under Static and Creep Loading. ACTA Universitatis Cibiniensis, 69(1), 1-8.

7. Glaskova, T., \& Aniskevich, A. (2009). Creep behavior of epoxy/clay nanocomposite. In Proceedings of international conference on composite materials.

8. Ogonna, M. C., Edith, M. C., \& Obinna, U. N. (2010). Characterisation and Study of the Creep Behaviour of Polypropylene/Calcium Carbonate Nanocomposites. Journal of Applied Sciences Research, 6, 1620-1626.

9. Tehrani, M., Safdari, M., \& Al-Haik, M. S. (2011). Nanocharacterization of creep behavior of multiwall carbon nanotubes/epoxy

nanocomposite. International Journal of Plasticity, 27(6), 887-901.

10. Yi-Luen, L. I., Chen, W. J., Chiang, C. L., \& Yip, M. C. (2011). Study on the Mechanical Properties and Creep Behaviour of Carbon 
Fiber Nano-Composites. MRS Online

Proceedings Library Archive, 1312.

11. Zandiatashbar, A., Picu, C. R., \& Koratkar, N. (2012). Control of epoxy creep using graphene. Small, 8(11), 1676-1682.

12. Ghosh, S. K., Prusty, R. K., Rathore, D. K., \& Ray, B. C. (2017). Creep behaviour of graphite oxide nanoplates embedded glass fiber/epoxy composites: Emphasizing the role of temperature and stress. Composites Part A: Applied Science and Manufacturing, 102, 166-177

13. Constantinescu, D. M., Picu, R. C., Sandu, M., Apostol, D. A., Sandu, A., \& Baciu, F. (2017). Behaviour of Epoxy Silica Nanocomposites Under Static and Creep Loading. ACTA Universitatis Cibiniensis, 69(1), 1-8

14. Cardarelli, F. (2000). Materials handbook (pp. 45-57). London etc.: Springer.

15. American Society for Testing and Materials International,1998," Standard Test Methods for Tensile, Compressive, and Flexural Creep and Creep-Rupture of Plastics"D2990.https://infostore.saigloba saiglobal.com/en-gb/standards/astm-d299001-828223/.

16. Yao, Z., Wu, D., Chen, C., \& Zhang, M. (2013). Creep behavior of polyurethane nanocomposites with carbon nanotubes. Composites Part A: Applied Science and Manufacturing, 50, 65-72.

17. Plaseied, A., \& Fatemi, A. (2009). Tensile creep and deformation modeling of vinyl ester polymer and its nanocomposite. Journal of Reinforced Plastics and Composites, 28(14), 1775-1788.

18. Abdulla, F. A., Fadhil, H. A., \& Abdulwahid, J. N. Experimental Study of the Creep Behaviour of Nano-Composites Carbon Fibres. 